\title{
Numerical Investigation on Heat Transfer Performance and Flow Characteristics in a Roughened Vortex Chamber
}

\author{
Hamad M. Alhajeria, ${ }^{a}$, Abdulrahman Almutairia ${ }^{a}$, Abdulrahman H. Alenezia a $^{\text {, }}$, Abdelaziz A.A. Gamil ${ }^{b}$ \\ ${ }^{a}$ Mechanical Power and Refrigeration Technology Department, College of Technological Studies, PAAET, Shuwaikh, Kuwait \\ ${ }^{b}$ Department of Power and Propulsion, Cranfield University, Cranfield, Bedfordshire MK43 OAL, UK
}

\section{Abstract}

In this study, an investigation of a vortex chamber was carried out to gain a full understanding of the nature of the vortex flow and the cooling capability inside the chamber. The paper discusses the effects on flow and heat transfer rates when the inside surface of the vortex chamber was roughened by adding flow turbulators to its wall. The turbulators took the shape of a rib with a square cross-section, the dimension of which varied between $0.25 \mathrm{~mm}$ and $2.00 \mathrm{~mm}$. The paper also presents the results of a comparative investigation of jet impingement and vortex cooling on a concave wall using different parameters, such as the total pressure loss coefficient, Nusselt number and thermal performance factor, to evaluate the cooling effectiveness and flow dynamics. Furthermore, the entropy generation in swirl flow with the roughened wall was assessed over a wide range of Reynolds numbers.

The results show that surface roughness considerably influences the velocity distribution, heat transfer patterns and pressure drop in the vortex chamber. The highest thermal performance factor takes place at rib heights of $0.25 \mathrm{~mm}$ and $0.50 \mathrm{~mm}$ with a low Re number. Further increase in rib height has an adverse impact on thermal performance. At a Reynolds number lower than 50000, it is highly recommended to use roughened vortex cooling to obtain the best thermal performance.

Keyword: Vortex chamber; Entropy; Nusselt number; Impingement; Roughened surface

\section{Introduction}

Vortex cooling is a promising method for industrial components subject to heavy thermal loads because of the additional turbulent mixing obtained. Swirl and impingement flows are common cooling techniques used in numerous engineering applications. Swirl flows are often used to maximise the heat transfer area and total energy flux away from the system in preference to other cooling methods [1-8]. A comparative study between vortex and jet impingement cooling techniques was investigated experimentally in $[9,10]$ for different flow rates. The results showed that the impingement cooling technique was more effective at a high flow rate, while both methods were comparable at a low flow rate.

Another experimental study [11] examined the temperature separation in a vortex chamber. 
The effects of cavity position and chamber configuration were investigated. It was reported that the pressure oscillation observed due to the shear layer behaviour generated by the leading edge of the cavity might have caused a temperature increase; and when the cavity was mounted vertically to the side wall, a large temperature separation was observed.

An experimental and numerical study was conducted by [12] to observe the effects of channel geometry and flow variables on cyclone cooling. The authors reported that the flow characteristics within the channel were dependent on the downstream shape of the channel and, in most cases, the outlet geometry defined the flow characteristics in the channel. The study [12] also observed that, because a high percentage of the mass flow tended to be close to the wall of the channel, owing to the swirling motion, it was relatively sensitive to the presence of ribs as a means of increasing heat transfer. Furthermore, the investigation indicated that the heat transfer rate increased proportionally with the Reynolds number and could be significantly affected by pressure fluctuations around the near-wall region. This behaviour was observed where favourable or adverse pressure gradients led to increased flow recirculation, sometimes observed as Görtler vortices.

The study in [13] showed that different jet nozzle geometries have different effects on the flow and heat transfer characteristics for the cooling of a gas turbine blade. The authors inserted nine jet nozzles into the vortex chamber and investigated different cross-sections at a constant Reynolds number. The authors in [14] investigated the cooling performance and flowed behaviour of a swirl chamber under rotating conditions. The geometry was based on the design used by [13], with the same nine jet nozzles. The research focused on the effects of rotation and concluded that the pressure increased along the axial flow direction, owing to the centrifugal force. It found that the heat transfer intensity decreased with decreasing rotational speed and increasing pressure drop, but the direction of rotation had no significant effect on the cooling air velocity or streamlines. In addition, it was shown that an increased density ratio increased vortex heat intensity.

The research continued with numerical simulation [15], in which the authors investigated the heat transfer and aerodynamic characteristics of gas turbine blade vortex cooling when rotation was present with bleed holes. It was observed that the suction effect of the bleed holes generated a new boundary layer on the chamber wall, which increased the heat transfer intensity and expanded the region of high $N u$. It was reported that the rotation reduced the heat transfer intensity as the centrifugal force pushed the cooling air towards a higher rotation radius, and when bleeding holes were present weakened the rotational flow in the chamber. In addition, the heat transfer intensity decreased with the increased rotation speed. It was found that the density ratio had no significant effect on vortex cooling.

The results presented in [15] also showed the effects of film hole geometry and mass flow rate on the vortex cooling of a gas turbine blade leading edge. The design was based on the geometry 
presented by [13] and different cases were compared. It was concluded that the existence of film holes improved the heat transfer by helping the generation of a more uniform pressure distribution, even though there was a mass loss due to flow through the holes. It was found that, overall, the static pressure coefficient and averaged Nusselt number decreased as the bleed ratio decreased.

The study in [16] was another numerical investigation of the separation phenomenon in a convergent cyclone separator with different throttle and main tube angles, length of tube, number of injectors and injection pressure, using a commercial computational fluid dynamics (CFD) programme. The authors concluded that increasing the throttle diameter decreased the heat transfer rate but that, at lower throttle angles, the change in efficiency was not significant, whereas at higher angles the efficiency increased with the throttle angle. It was also reported that higher injection pressure increased the efficiency and there was an optimum length to the tube. The study [16] concluded that initially, as the number of jet nozzles increased, efficiency increased but that, after reaching a certain number, it started to decrease.

The study in [17] showed the effects of multiple slots in a gas turbine blade on the flow pattern in a swirl chamber. The authors used two different swirl chamber geometries and numbers of inlet slots at different locations. The results were validated against the experimental data of [9]. They indicated that the use of different configurations might be more efficient in terms of heat transfer, but that space limitations make the traditional arrangements more applicable. It was also observed in this paper that three inlets from different directions gave the best results, and that heat transfer efficiency could be improved significantly with well-designed and better inlet configurations. Finally, the effects on the swirling flow of three outlet geometries - horizontal, tangential and $180^{\circ}$ bend - were investigated in [18]. The results showed that outlet geometries had a negligible effect on the heat transfer coefficient.

Double swirl cooling was investigated as a technique to improve the heat transfer characteristic and to reduce the pressure drop in [17,19]. A numerical investigation was performed for the swirling flow in a tube using Large Eddy Simulation (LES), Hybrid LES/Reynolds-Averaged Navier-Stokes (RANS) and RANS [20]. The results showed that LES and LES/RANS gave good agreement with the experimental data. Another study used Detached Eddy Simulation (DES) to investigate the flow field and heat transfer characteristics inside a swirl tube [21]. The results were validated against experiment and good agreement found.

A grooved swirl cooling tube with different depths of grooves was investigated by [22], with the emphasis on heat transfer and pressure drop characteristics of the turbine blade leading edge swirl channel. The study simulated four flow rates with a Reynolds number ranging from 10000 to 40000 . The result showed that a grooved swirl tube reduced the pressure drop compared to a smooth channel and, furthermore, the total heat transferred by the cooling channel increased. 
A comparison of studies by CFD and laser Doppler anemometry (LDA) of the inside of a vortex chamber of a turbine blade was carried out by [23]. The research focused on the inlet to outlet ratio and its effect on chamber flow. The numerical simulation and the experiment results were close, though with some deviation near the inlet owing to the inlet flow's interaction with the vortex core. The project was extended to investigate the heat transfer inside the vortex chamber [24], and it was concluded that the heat transfer was maximum when the inlet to outlet ratio was unity.

Three turbulence models, k- $\omega$ SST, standard k- $\varepsilon$ and k- $\varepsilon$ RNG, were used to investigate flow field and heat transfer characteristics in swirling cooling in [25]. The results showed that the RNG $\mathrm{k}-\varepsilon$ model was the most accurate when compared to the experimental data.

Most investigations reported in the literature were conducted with a smooth vortex chamber; none has explored the roughened surface. The influence of internal roughening of the wall of a vortex chamber on the flow field, heat transfer, pressure loss, thermal performance factor and entropy generation was investigated in the present research. The internal wall of the vortex chamber was roughened by adding ribs of different heights. Furthermore, the study investigated the ability of turbulence models to represent flow behaviour in the ribbed vortex chamber for both steady and unsteady simulation.

\section{Geometry and Boundary Conditions}

The numerical validation was conducted on the same experimental geometry as used in [23], as presented in Figure 1. The proposed vortex chamber had an opposite stream for the inlet and outlet. The chamber width was $60 \mathrm{~mm}$, the diameter was $100 \mathrm{~mm}$ and the inlet and the exit ducts were rectangular in cross-section, $8 \mathrm{~mm}$ high and $60 \mathrm{~mm}$ wide (Figure 2). The hybrid mesh grid of the computational domain is presented in Figure 3. The mesh gradient changed from 3.4 million cells to 7.5 million cells to predict the temperature and dynamic boundary layers close to the wall. A grid dependence study was carried out for three meshes at low and high Reynolds number. The deviation of the average Nusselt number was less than $1 \%$ for the medium and fine mesh (Figure 4). For all computations, the $\mathrm{y}^{+}$values of the first cell were less than unity for all Reynolds numbers used.

All simulations in the present study were carried out for the air at Prandtl number $\operatorname{Pr}=0.73$. The constant surface temperature of the smooth heated wall was chosen to be $T_{\text {wall }}=332 \mathrm{~K}$. In Figure 2 the hot wall is coloured red. The remaining, blue-coloured chamber walls are considered to be adiabatic. At the inlet boundary of the chamber, a constant velocity was set for several Reynolds numbers with a constant inlet temperature of $\mathrm{T}_{\text {in }}=298[\mathrm{~K}]$. The constant value of pressure was specified at the outlet boundary. The flow density and viscosity were $1.21 \mathrm{~kg} / \mathrm{m}^{3}$ and $1.8 \times 10^{-5} \mathrm{Ns} / \mathrm{m}^{2}$ $\mathrm{r}$, respectively. 


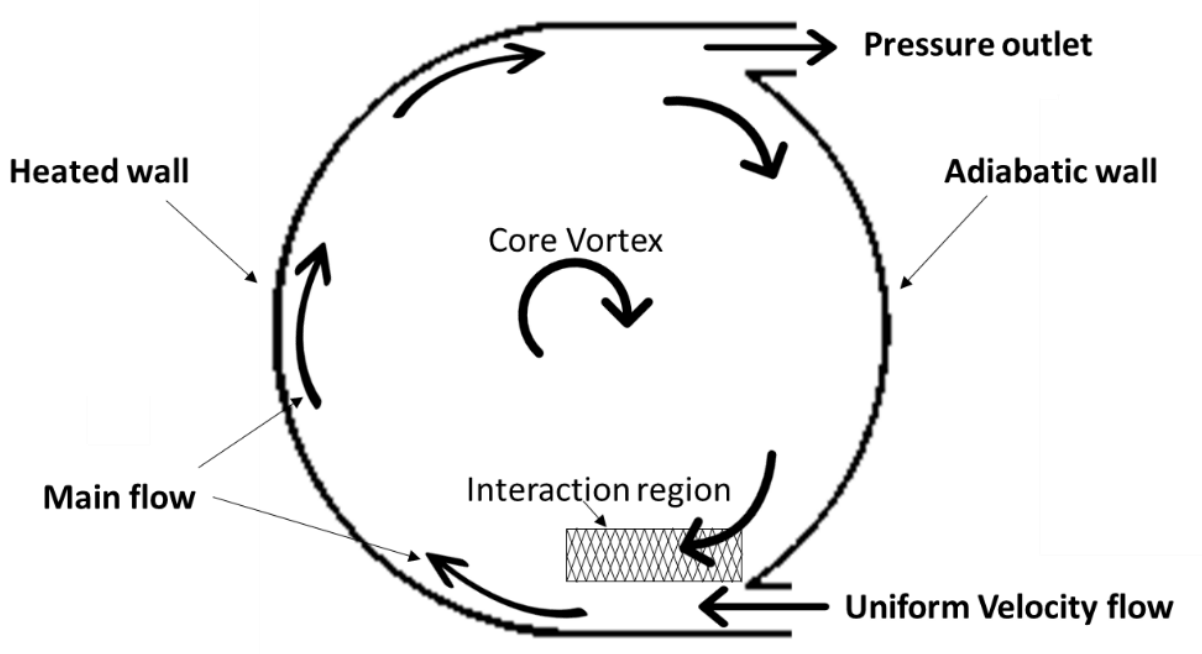

Figure 1 Sketch of the geometrical configuration.

(a)

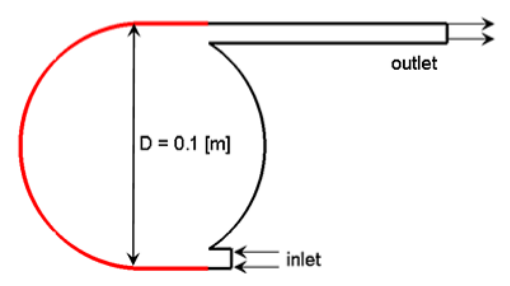

Adiabatic

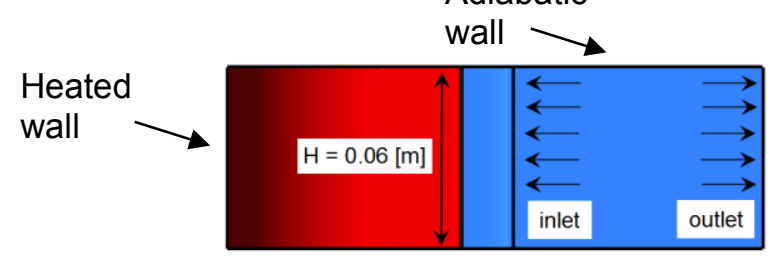

(b)
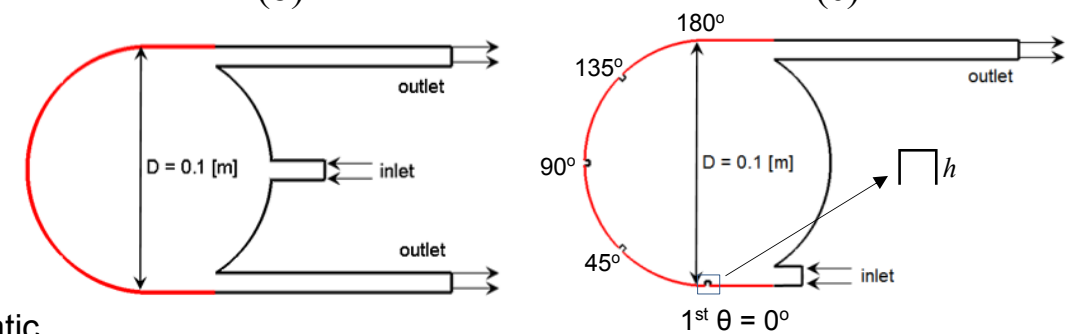

Figure 2 Geometry of (a) smooth vortex chamber, (b) jet impingement and (c) roughened vortex chamber.

\section{Numerical Model}

The computational simulation was carried out using FLUENT v18.0. A turbulence model study was performed in this simulation, adopting four turbulence models - steady RANS RNG k- $\varepsilon$; K- $\omega$ SST; K-kL; and eddy-resolving improved delayed detached eddy simulation (IDDES) - to investigate the fluid flow characteristics for 3-D swirling and turbulent flow in the chamber [26,27]. Generation of turbulence at the inlet section for the IDDES calculations employed the so-called vortex method.

The equations were solved through the implicit point Gauss-Seidel method, using the RhieChow flux correction [28] to suppress pressure oscillations. An algebraic multi-grid solver was 
applied to accelerate convergence by computing the corrections on a series of grids. The SIMPLEC method was used for pressure-velocity coupling in the RANS/URANS cases, with 20 sub-iterations per time step performed in unsteady cases. The NITO fractional step method [29] was used for pressure-velocity coupling in the IDDES cases. The inviscid fluxes in the momentum equations were approximated using the second-order upwind scheme in the RUNS/URANS case and the centred scheme in the IDDES case.

In this study, the wall velocity was set to zero; hence the vortex chamber was stationary and there was no slip at the walls. The heated wall was defined as fixed temperature and the rest were adiabatic surfaces. The physical constants of the fluid, such as the density and viscosity used, matched the experimental value. Turbulence intensity was assumed to be 5\%. The inlet velocities were based on the inlet flow rate of the experiment.

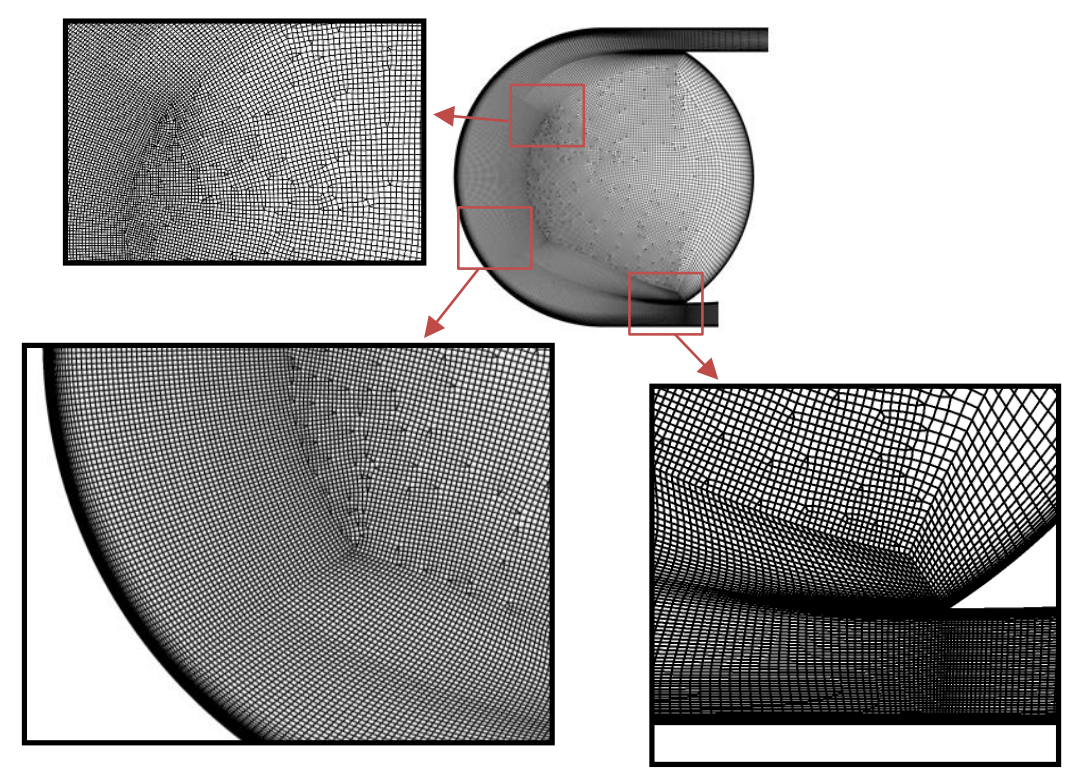

Figure 3 Mesh for computation domain.

\section{Governing Equations}

The governing differential equations for the conservation of mass, momentum and energy were as follows.

Conservation of mass:

$$
\frac{\partial \rho}{\partial t}+\nabla \cdot(\rho \vec{u})=0
$$

Momentum:

$$
\frac{\partial(\rho \vec{u})}{\partial t}+\nabla \cdot(\rho \vec{u} \otimes \vec{u})=-\nabla p+\nabla \cdot \overline{\bar{\tau}}+S_{M}
$$


Energy:

$$
\frac{\partial\left(\rho I_{t o t}\right)}{\partial t}-\frac{\partial p}{\partial t}+\nabla \cdot\left(\rho \vec{u} I_{t o t}\right)=\nabla \cdot(k \nabla T)+\nabla \cdot(\vec{u} \cdot \overline{\bar{\tau}})+\vec{u} \cdot S_{M}+S_{E}
$$

The pressure loss coefficient is referred to as the friction factor and can be calculated as:

$$
\xi=\frac{2 \Delta p_{t}}{\rho u_{i n}^{2}}
$$

where $\Delta \mathrm{p}_{\mathrm{t}}$ is the total pressure difference between the inlet and outlet of the chamber and $\mathrm{u}_{\text {in }}$ is the inlet velocity.

At constant surface temperature, the average heat transfer coefficient $(h)$ and average $(\mathrm{Nu})$ $[30,31]$ can be expressed as:

$$
\begin{gathered}
h=\int \frac{q_{w}}{T_{w}-T_{b}} \\
N u=\frac{h D}{k}
\end{gathered}
$$

The globally averaged thermal performance factor is defined as the ratio of heat transfer augmentation to frictional loss penalty [32], and is written as:

$$
\frac{N u / N u_{o}}{\left(f / f_{o}\right)^{1 / 3}}
$$

where

$$
f_{o}=\frac{0.3164}{R e_{D}^{0.25}}
$$

$f_{o}$ is the baseline friction factor for a smooth chamber, which can be determined by the Blasius power law correlation. $\mathrm{Nu}_{\mathrm{o}}$ is defined as the Nusselt number for fully developed, non-swirling, turbulent flow in the pipe, which can be calculated using the Dittus-Boelter correlation shown below:

$$
N u_{o}=0.023 \operatorname{Re}_{D}^{0.8} \operatorname{Pr}^{n}
$$

where $\mathrm{n}$ is equal to 0.4 when heating the fluid, and 0.3 when cooling the fluid.

The total entropy generation rate, $\mathrm{S}_{\text {total }}$, is calculated as a post-processed quantity as:

$$
\mathrm{S}_{\text {total }}=\mathrm{S}_{\text {gen,heat }}+\mathrm{S}_{\text {gen,fluid }}
$$


where $S_{\text {gen,heat }}$ is the entropy generation rate due to heat transfer and $S_{\text {gen,fluid }}$ is the entropy generation rate due to friction. Following $[33,34]$, these can be written as:

$$
S_{\text {gen,heat }}=\frac{\lambda_{\text {eff }}}{T_{i}^{2}}\left[\left(\frac{\partial T}{\partial x}\right)^{2}+\left(\frac{\partial T}{\partial y}\right)^{2}+\left(\frac{\partial T}{\partial z}\right)^{2}\right]
$$

where the effective thermal conductivity is the sum of turbulent and laminar thermal conductivities:

$$
\lambda_{\text {eff }}=\lambda_{\text {turb }}+\lambda_{\text {lam }}
$$

The entropy generated due to fluid friction is calculated as in [33]:

$$
S_{\text {gen }, \text { frict }}=\frac{\mu_{\text {eff }}}{T_{i}}\left\{2\left[\left(\frac{\partial u}{\partial x}\right)^{2}+\left(\frac{\partial v}{\partial y}\right)^{2}+\left(\frac{\partial w}{\partial z}\right)^{2}\right]+\left(\frac{\partial u}{\partial y}+\frac{\partial v}{\partial x}\right)^{2}+\left(\frac{\partial u}{\partial z}+\frac{\partial w}{\partial x}\right)^{2}+\left(\frac{\partial v}{\partial z}+\frac{\partial w}{\partial y}\right)^{2}\right\}
$$

where the effective viscosity is the sum of turbulent and thermal laminar viscosities;

$$
\mu_{\text {eff }}=\mu_{\text {turb }}+\mu_{\text {lam }}
$$
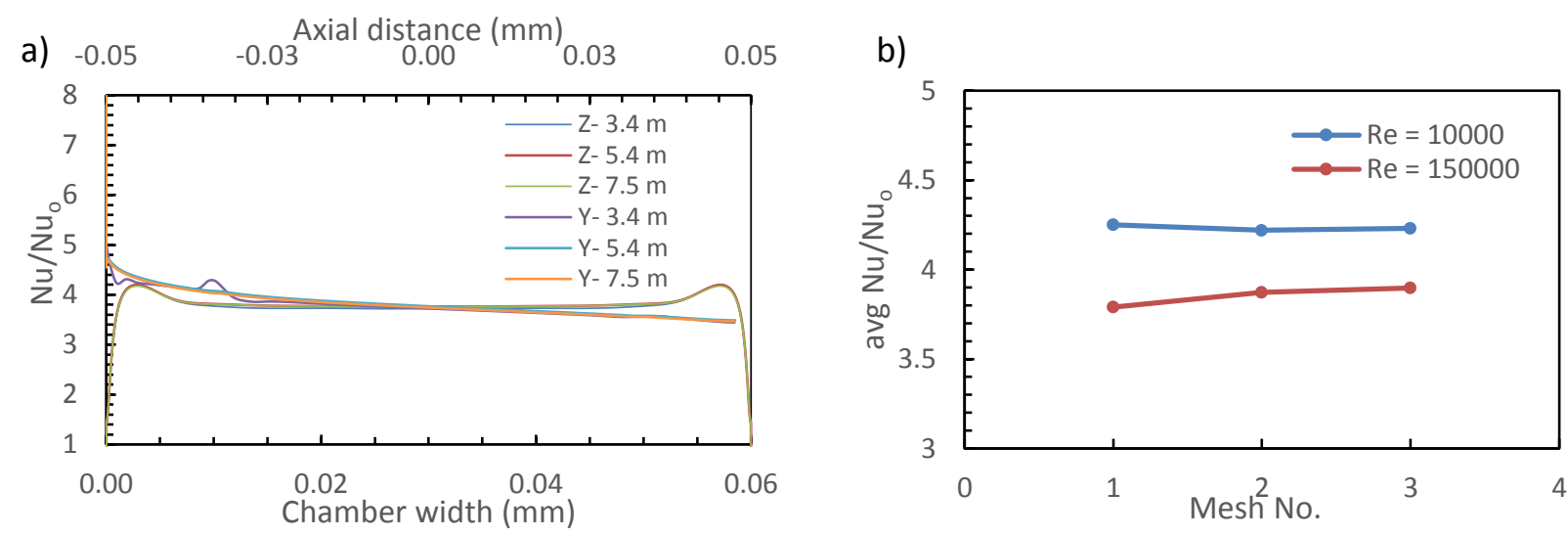

Figure 4 Grid independence study a) Nusselt number ratio plotted along the chamber width (Z) and chamber axial distance (Y) b) Average Nusselt number ratio for low and high Re number

\section{Validation}

The proposed geometry was adopted after comparison to geometries reported in the literature in order to give results that can be compared with those obtained by other researchers. The validation of the turbulence models against experimental results is also reported.

A grid independence study was carried out to ensure that the mesh size used had little influence on the results obtained. The model selected should have the ability to predict the relevant flow conditions and provide an accurate simulation of the swirl flow and heat transfer. Four different turbulence models, RNG k- $\varepsilon$ model, K-KL model, SST k- $\omega$ model and hybrid IDDES model, were used. The convergence criteria were fixed at $\left(10^{-5}\right)$ for the conservation of mass and momentum.

Figure 5 shows the normalised swirl flow velocity $\mathrm{Ux} / \mathrm{Ub}$ profiles for the smooth vortex 
chamber at the chamber centre from the inlet $\theta=0^{\circ}$ to outlet $\theta=180^{\circ}$ of the chamber. Predictions of both K- $\varepsilon$ RNG and k- $\omega$ SST turbulence models showed good agreement with the experimental values near the inlet and an outlet. However, these two turbulence models did show a small divergence from measured values at $y=25 \mathrm{~mm}$, perhaps owing to the location criteria where the flow separates at the intersection of the main flow and the core vortex near the outlet. Figure 6 represents the normalised swirl flow velocity between the stagnation point and the inner wall. The velocity profiles for RNG and SST models are almost coincident with the experimental values along the chamber. The IDDES model showed a constant difference through the chamber.

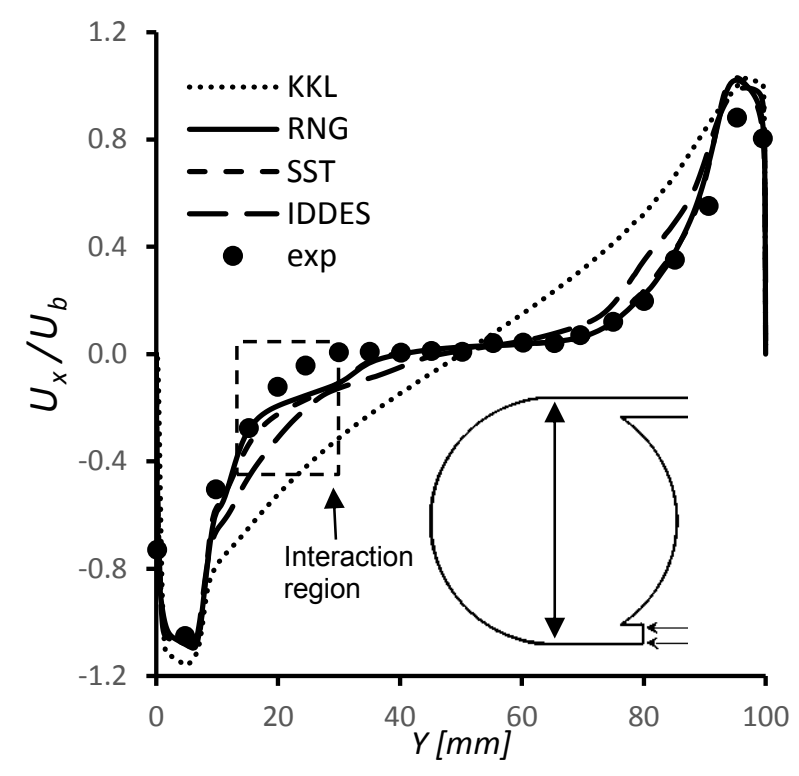

Figure 5 Swirl flow at $\Theta=270^{\circ}-90^{\circ}$, for

$$
R e=58800 \text {. }
$$

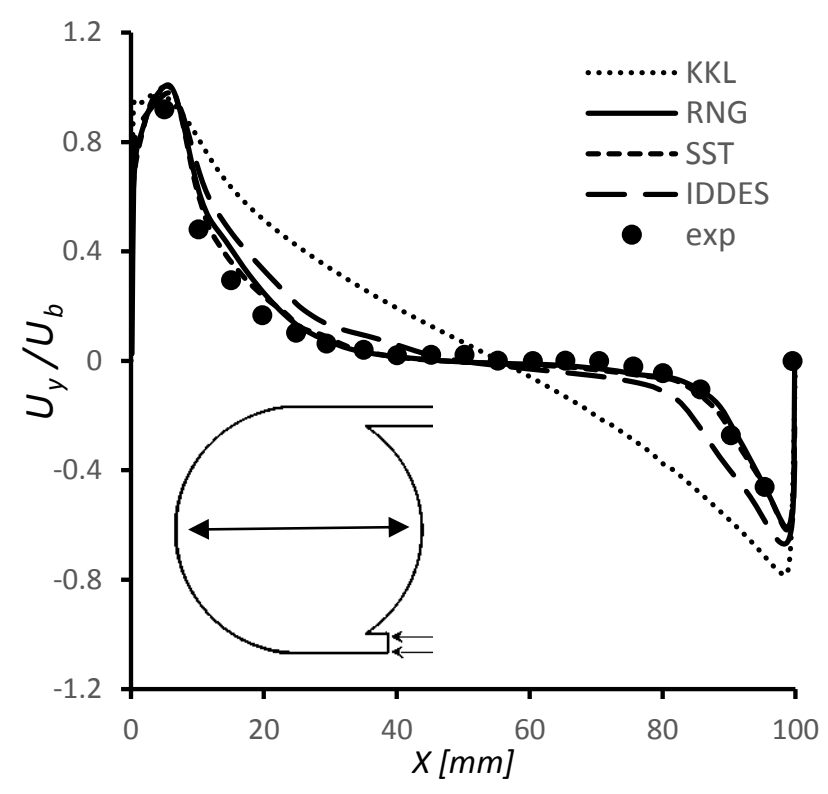

Figure 6 Swirl flow at $\theta=180^{\circ}-0^{\circ}$, for

$$
\operatorname{Re}=58800 \text {. }
$$

The average Nusselt numbers for the four turbulence models are presented in Table 1. The IDDES turbulence model gave the best prediction of the experimental Nusselt number, with only 4.8\% difference. Next was the RNG model with 7.3\% difference. The SST model showed 9.7\% difference. This latter figure is close to the results of [35], where the difference between SST predicted values and measured values of average Nusselt numbers ranged between $8 \%$ and $13 \%$. The RNG k$\varepsilon$ model was adopted for all the following calculations, not only because of its ability to predict the heat transfer and velocity profiles more accurately, but also its low computational cost. 
Table 1 Nusselt number at Re 58800

\begin{tabular}{llll} 
Turbulence model & Nusselt number & $\mathrm{Nu} / \mathrm{Nu}_{0}$ & $\%$ \\
\hline K- $\varepsilon$ RNG & 754 & 4.4 & 7.3 \\
\hline K- $\omega$ STT & 769 & 4.5 & 9.7 \\
\hline IDDES & 749 & 4.3 & 4.8 \\
\hline Exp & 695 & 4.1 &
\end{tabular}

\section{Applicability of Turbulence Model}

To show the ability of the turbulence model to correctly predict the flow type, the RNG k- $\varepsilon$ model was compared with steady, quasi-steady and unsteady flow. Figure 7 presents the map of the flow regimes in the vortex chamber with and without a roughened surface. At a rib of height $0.25 \mathrm{~mm}$, the flow behaviour is comparable to the smooth vortex chamber, which primarily generates steady turbulent flow.

In this study, with $10000 \leqslant \operatorname{Re} \leqslant 150000$, and with rib height of $h_{R I B} \leq 1.00 \mathrm{~mm}$, we observed quasi-steady flow and steady turbulent flow without large-scale separation zones in the vortex chamber, which are well described by the steady RANS model. Quasi-steady flow was characterized by small temporal changes $( \pm 3 \%)$ in the flow.

For $h_{R I B}=2.00 \mathrm{~mm}$ and Re number of 20000 and higher, the flow was unsteady with largescale separation zones and strong changes in flow characteristics $( \pm 20 \%)$ with time. This type of flow is difficult to predict using the steady RANS and so $h_{R I B}=2.00 \mathrm{~mm}$ requires investigation using the unsteady RANS.

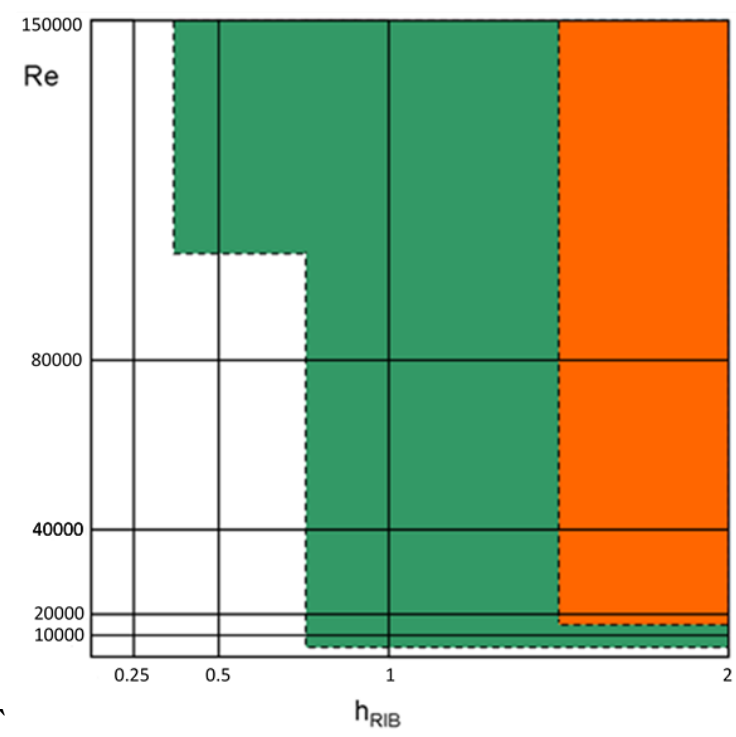

Figure 7 Map of the flow regimes: white-steady; green-quasi-steady; red-unsteady. 


\section{Results}

Concave wall cooling is sensitive to jet position and wall configuration. In order to analyse the effects of the flow with maximum efficiency, the same configuration with the same boundary conditions should be used for all flow rates. First, a comparison was made between the vortex cooling and jet impingement on a smooth concave wall and then the roughness element to enhance the heat transfer was added to the vortex chamber.

\subsection{Jet Impingement and Vortex Cooling Comparison}

This section reports the investigation of the thermal performance of the vortex chamber with jet impingement on the concave wall, as shown in Figure 2 (a) and (b). A comparison was carried out to find the optimal cooling design for a chamber with a diameter equal to the jet target distance. The thermal performance factor and average Nusselt number were calculated.

Figure 8 presents the results for the average Nusselt number, pressure drop, average normalised Nusselt number and thermal performance factor for a range of Reynolds numbers. The results show that the pressure drop for jet impingement is heavily affected by Re: as Re decreases, the pressure drop increases significantly. They also show that the pressure drop is much greater for jet impingement than for vortex cooling. In the jet impingement cooling technique, the relatively high-pressure drop may be attributed to the kinetic energy loss after leaving the nozzle and frictional losses near the wall.

The heat transfer, as expressed by the Nusselt number, reduces at low Re number owing to the channel flow affecting the inlet jet. However, this is not the case for vortex cooling, which is primarily affected by the concave wall and the chamber core vortex. The normalised Nusselt number shows that heat transfer for low Reynolds numbers is higher in the vortex chamber and, as the Reynolds number increases, jet impingement rises compared to the vortex chamber at $\operatorname{Re}>50000$. The thermal performance factor presents the heat transfer with respect to the pressure drop within the system. Results show that this factor is greater for the vortex than jet impingement. At a low Reynolds number, the thermal performance factor for the vortex chamber is $63 \%$ higher than jet impingement and $41 \%$ at high speed. At low Reynolds number, vortex cooling delivers higher heat transfer rate relative to the jet impingement cooling with lower pressure drop rate due to less dynamic losses. In contrast, at high Reynolds number the impingement cooling technique introduce high transfer rate while the pressure drop rate remains higher for the same reason. 


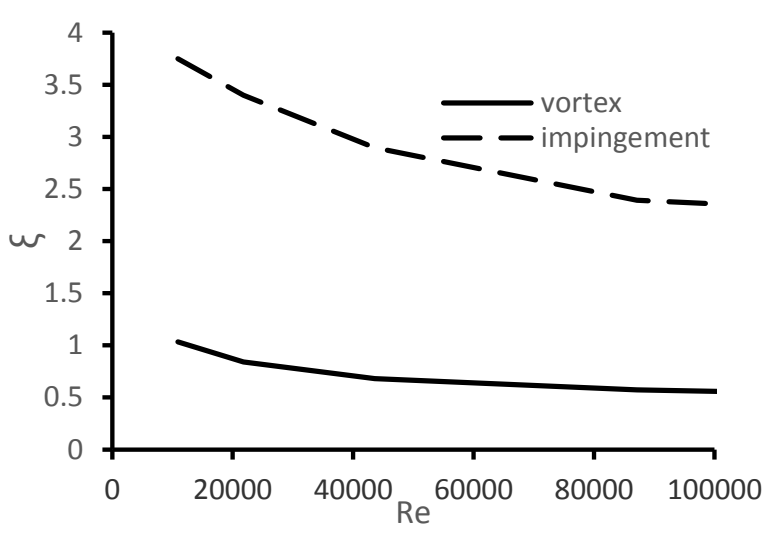

(a)

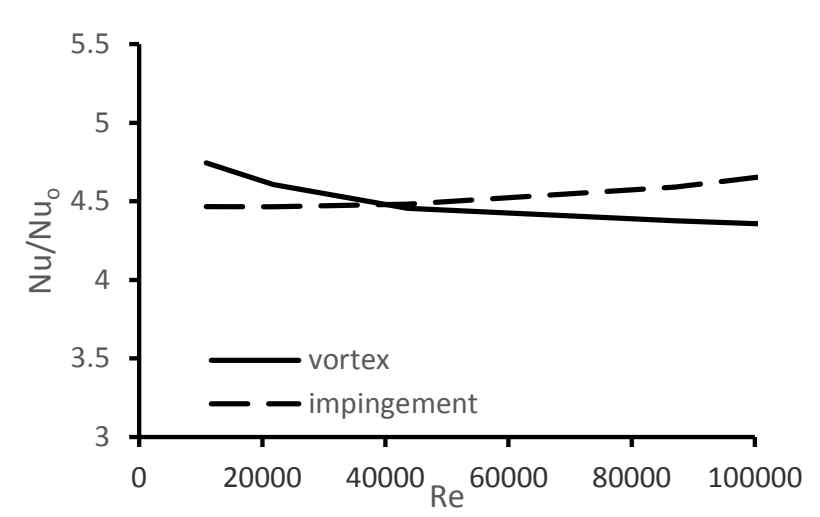

(c)

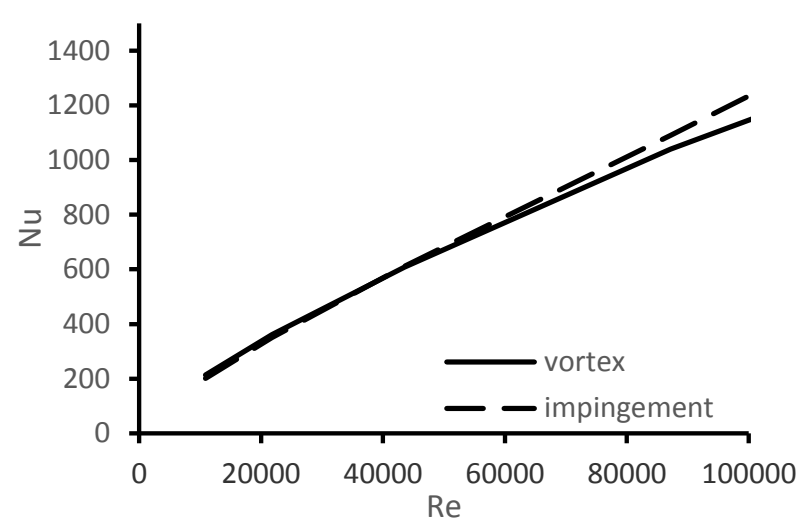

(b)

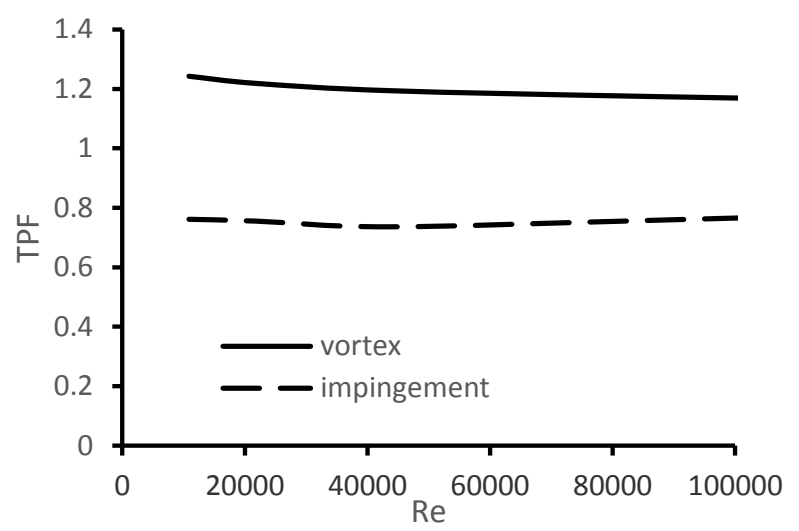

(d)

Figure 8 (a) Pressure drop, (b) Nusselt number, (c) Normalised Nusselt number, (d) thermal performance factor, all plotted against Reynolds number for both vortex and jet impingement.

\subsection{Effects of Rib Heights}

The following results present the effects of a roughening of the surface on heat transfer characteristics for the vortex chamber across a wide range of Reynolds numbers from 10000 to 100000 , for square ribs of four heights added to the heated surface: $0.25 \mathrm{~mm}(\mathrm{e}=0.0625), 0.50 \mathrm{~mm}$ $(\mathrm{e}=0.125), 1.00 \mathrm{~mm}(\mathrm{e}=0.25)$ and $2.00 \mathrm{~mm}(\mathrm{e}=0.5)$, where $\mathrm{e}=\mathrm{h}_{\mathrm{rib}} /(\mathrm{H} / 2)$. These effects are demonstrated in terms of velocity ratio, Nusselt number, wall averaged Stanton number (St), total pressure loss coefficient $(\xi)$, pressure coefficient (cp) and thermal performance factor (TPF).

Figure 9 shows contours of the normalised velocity, the ratio of the velocity magnitude and the bulk axial velocity for the smooth vortex chamber and vortex chamber with roughened surface at Reynolds numbers in the range 10000 to 80000 . For the smooth case, it is clear that the velocity increases near the heated wall and decreases in the direction towards the chamber centre, indicating a dominant high swirl motion. Between the wall and centre zones, the velocity decreases gradually for all Reynolds numbers. With increasing Reynolds number, the core vortex in the central zone increases in area/volume, except for the case of rib height $2.0 \mathrm{~mm}$. The size of the core vortex is 
highly affected by the main flow near the heated wall, with the core vortex size increasing as the main flow near the heated wall increases.

The main flow is adjacent near the wall for the smooth case at all Reynolds numbers. When ribs are introduced, the main flow increasingly shifts away from the wall as the rib height increases from 0.25 and $0.50 \mathrm{~mm}$. Once the rib height reaches $1.00 \mathrm{~mm}$, the flow moves significantly further from the wall while still preserving the same form. When the rib height reaches $2.00 \mathrm{~mm}$, the ribs divert the flow further from the wall towards the core, resulting in a circulation region near the heated wall between the first three ribs and decreasing the size of the core vortex. Figure 8 shows that the presence of the ribs affects the main flow speed at lower Reynolds numbers, but at high Reynolds numbers the flow overcomes the effect of the ribs and maintains its high speed along the chamber for rib heights $\leqslant 1.0 \mathrm{~mm}$.

The value of $\xi$, for the vortex chamber with smooth and roughened walls for Reynolds numbers in the range 10000 to 100000, is presented in Figure 10 (a). It can be seen that $\xi$ decreases gently with an increase in Reynolds number, owing to the chamber's high core flow speed at low values of Reynolds number. In comparison, as the rib height increases, the pressure loss coefficient also increases, because the roughened surface creates more vortices in the fluid flow downstream. This helps increase the pressure difference between the inlet and outlet of the vortex chamber. At Reynolds number of 100000, the vortex chamber with rib heights of $2.00 \mathrm{~mm}$ and $1.00 \mathrm{~mm}$ has pressure loss coefficients higher by about twice and 1.6 times, respectively, than for the smooth vortex chamber. 


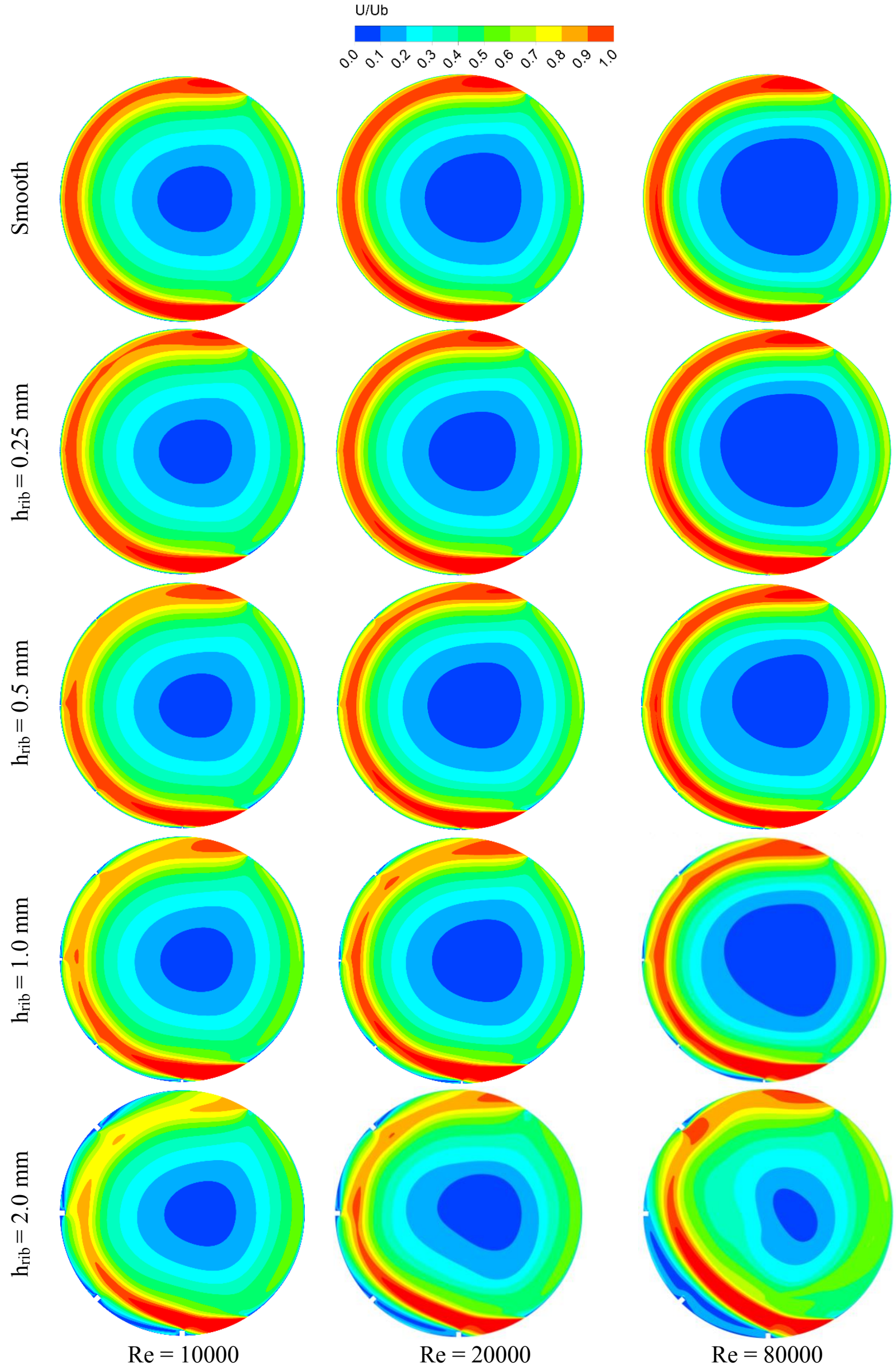

Figure 9 Normalised velocity contours for smooth and roughened wall at the middle of the chamber. 
(a)

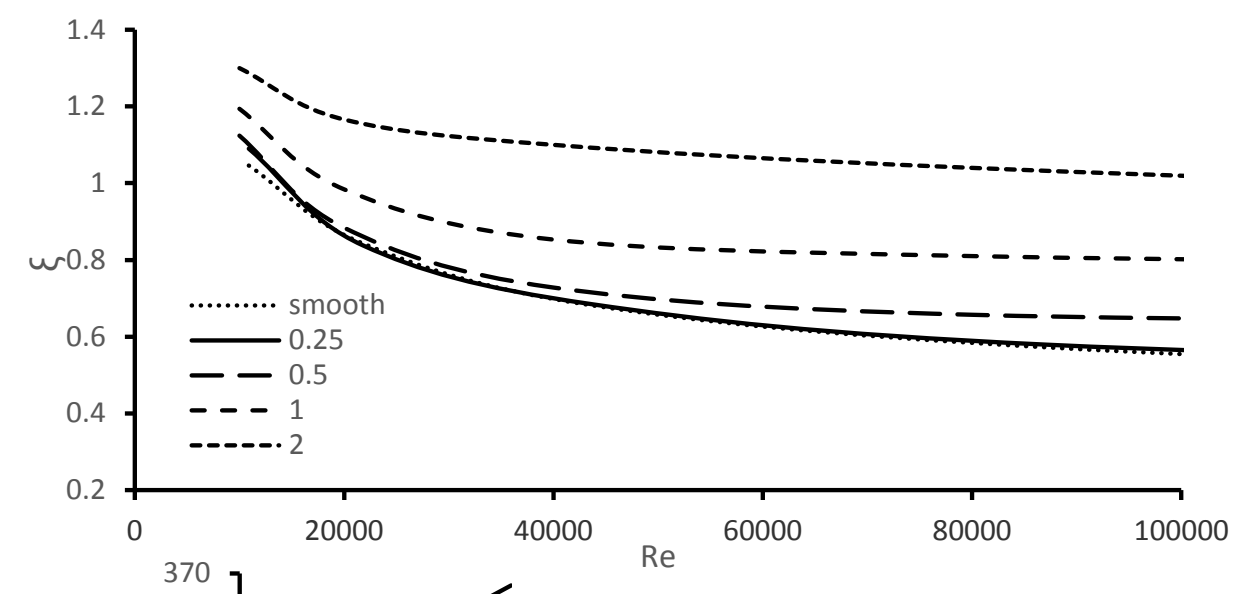

(b)
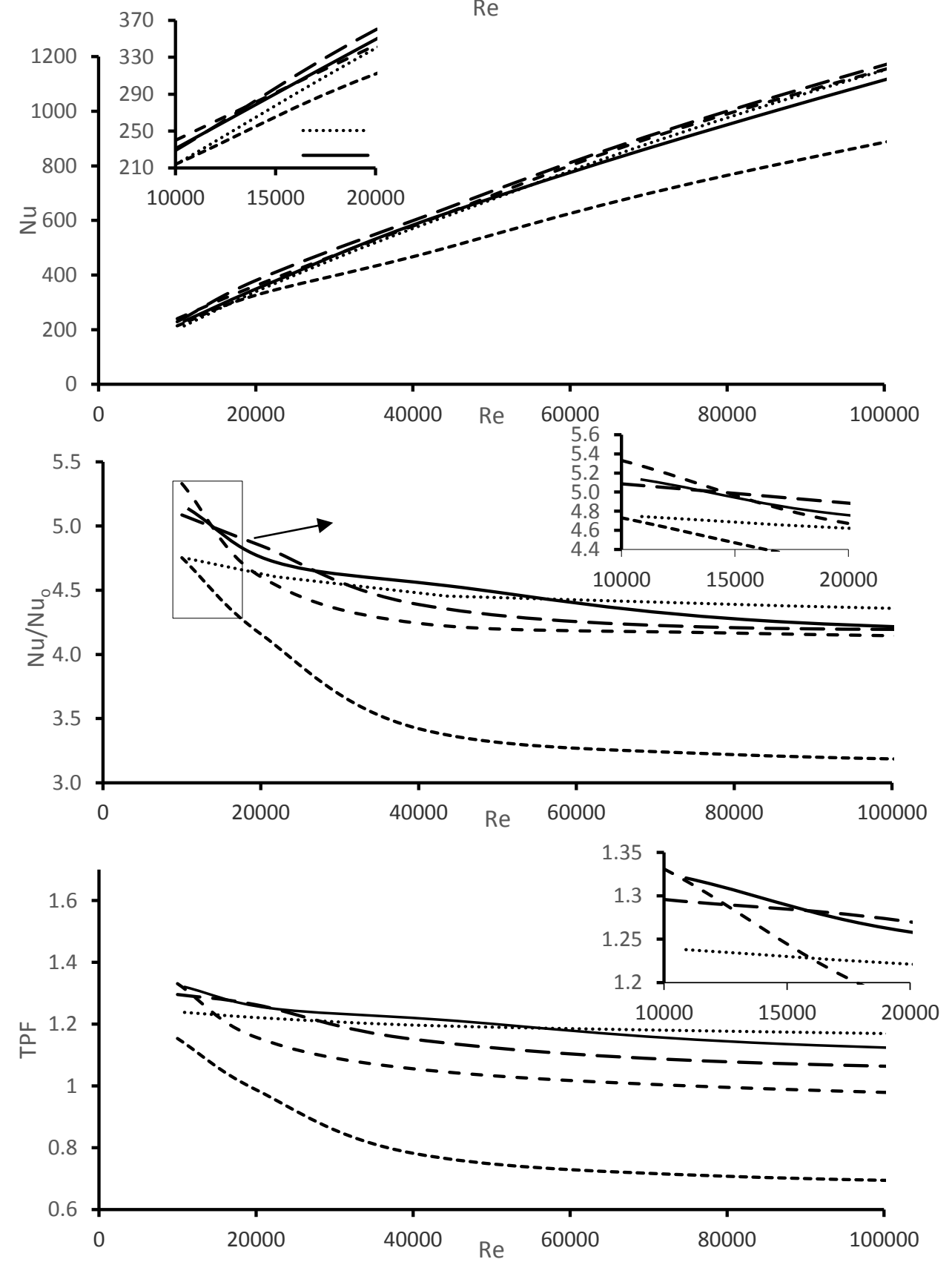

(c)

Figure 10 (a) Total pressure loss coefficient, (b) Nusselt number, (c) Normalised Nusselt number, (d) Thermal performance factor; all plotted against Reynolds numbers in the range 10000 to 100000 for smooth and rib roughened vortex chamber (rib heights: $0.25 \mathrm{~mm}, 0.50$ $\mathrm{mm}, 1.00 \mathrm{~mm}$ and $2.00 \mathrm{~mm}$ ). 
The normalised $\mathrm{Nu}\left(\mathrm{Nu} / \mathrm{Nu}_{\mathrm{o}}\right)$ for the wall with $\mathrm{h}_{\text {rib }} \geqslant 1.00 \mathrm{~mm}$ is higher than for the smooth case, i.e. at Reynolds number $<20000$. Figure 10 (c) shows that for a Reynolds number higher than 50000, the wall shows better heat transfer when smooth than when roughened. Furthermore, the value of $\mathrm{Nu} / \mathrm{Nu}_{\mathrm{o}}$ for a rib height of $2.00 \mathrm{~mm}$ shows a $26 \%$ decrease in heat transfer at high values of Reynolds number compared to the smooth chamber.

Figure 10 (d) shows the thermal performance factor as a function of Reynolds number for the vortex chamber with and without ribs. For all rib heights, the thermal performance factor decreases as the Reynolds number increases. This is due to reducing $\mathrm{Nu} / \mathrm{Nu}_{\mathrm{o}}$ with an increase in the Reynolds number in the vortex chamber, as shown in Figure 10 (c). At a low Reynolds number, a high thermal performance factor can be achieved from the ribbed vortex chamber at all rib heights. The rib height of height $0.25 \mathrm{~mm}$ shows high thermal performance at low and middle Reynolds numbers. Here, the heat transfer is enhanced; the pressure loss is close to that for the smooth wall case and lower than for rib heights $\geqslant 0.50 \mathrm{~mm}$. Also, the figure shows that the ribbed vortex chamber with rib height of $2.00 \mathrm{~mm}$ has the lowest thermal performance factor because it has the highest total pressure loss, as shown in Figure 10 (a).

A normalised Nusselt number between all ribs in the chamber is plotted in Figure 10, for Reynolds numbers 10000, 20000 and 40000, for all rib heights. The $\mathrm{x}$-axis represents the curve angle between each pair of ribs, and the dotted line represents the normalised $\mathrm{Nu}$ for the smooth chamber. For the smooth chamber, the normalised Nusselt number is high at the beginning of the chamber owing to the high tangential flow velocity entering the chamber and the beginning of the concave wall, which reduces the thermal boundary layer in that region. The normalised Nusselt number decreases gradually along the concave wall, which is to be expected as the flow develops. Furthermore, as the Reynolds number increases, so the maximum normalised Nusselt number at the beginning of the chamber increases. 

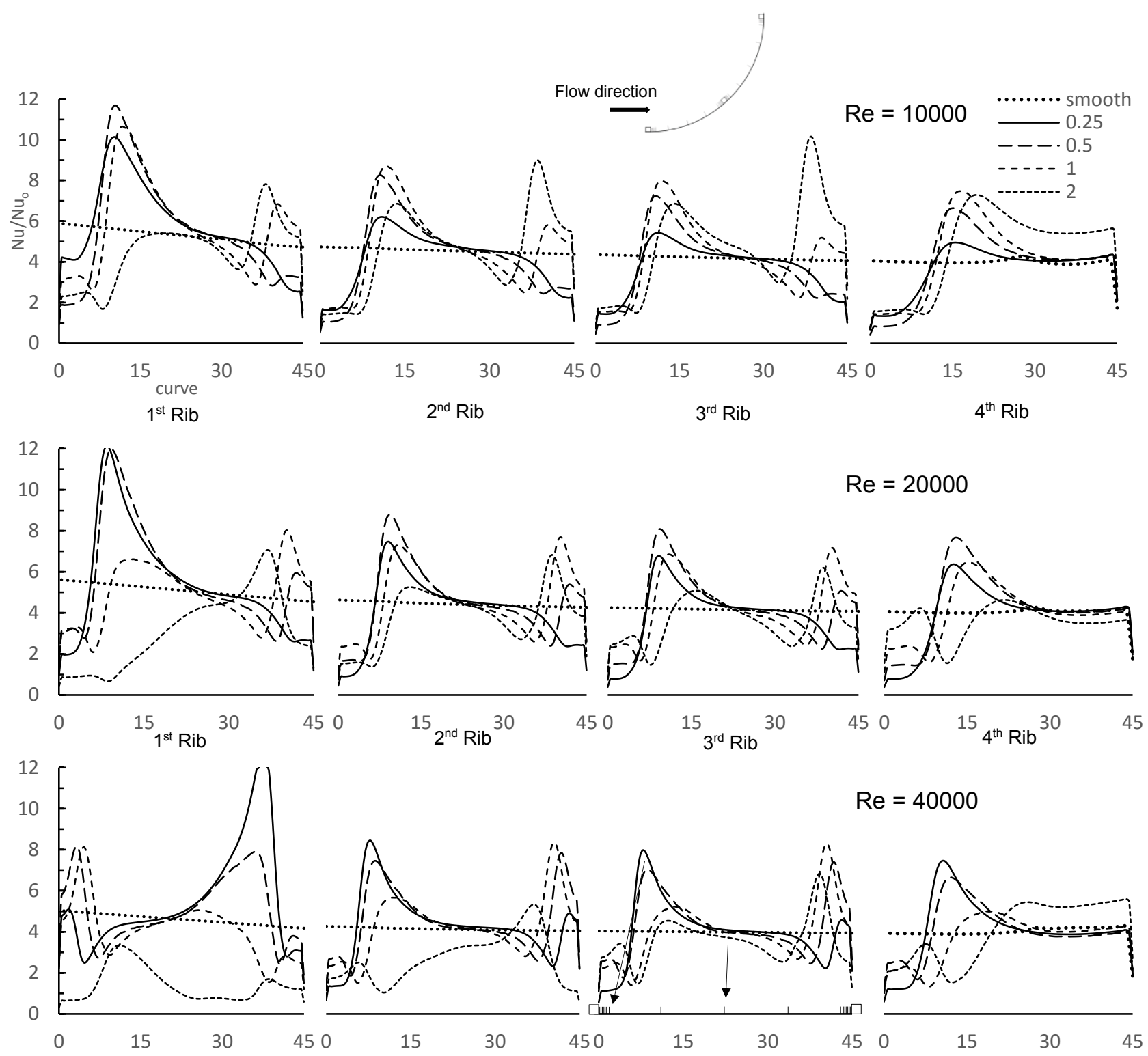

$\mathrm{Re}=40000$

Figure 11 Normalised Nusselt number downstream of each of the four rib positions for smooth and rib roughened wall.

The normalised Nusselt number for rib height of $0.25 \mathrm{~mm}$ is plotted as a solid continuous line in Figure 10. It can be seen that $\mathrm{Nu} / \mathrm{Nu}_{\mathrm{o}}$ is a maximum at the first rib and then decreases relatively after each subsequent rib. The peak in $\mathrm{Nu} / \mathrm{Nu}_{\mathrm{o}}$ downstream of the first rib represents the circulation region where the flow reattaches to the wall after being separated by the rib and generates a vortex, which is expected in flow over ribbed surfaces. As the flow advances to the following ribs, the peak from the reattachment decreases considerably until the last (fourth) rib, when the peak starts to fade away.

As the Reynolds number increases, the $\mathrm{Nu} / \mathrm{Nu}_{0}$ peak at the first rib increases for a rib height of $0.25 \mathrm{~mm}$. In addition, as the Re number increases, the peaks for the second, third and fourth ribs increase and become steady. A small secondary peak appears at Reynolds number 40000, upstream of each rib in the chamber, owing to the vortex intensity generated by the stagnation region at those points, which impinge on the wall in the opposite direction to the main flow. Large vortices 
downstream of each rib result in a region of low $\mathrm{Nu} / \mathrm{Nu}_{\mathrm{o}}$ before the peak.

The highest $\mathrm{Nu} / \mathrm{Nu}_{\mathrm{o}}$ peak occurs for a rib of height $0.50 \mathrm{~mm}$ and Reynolds number 10000; thereafter, for this height of rib, the initial peak progressively decreases with an increase in Reynolds number. The same pattern of behaviour is followed by the peaks generated by the rib of height 1.00 $\mathrm{mm}$, though in this case the peak decreases until it clearly falls below the $\mathrm{Nu} / \mathrm{Nu}_{\mathrm{o}}$ value for the smooth wall at Reynolds number of 40000 . The rib of height $2.00 \mathrm{~mm}$ has no peak near the inlet because the flow is diverted from the wall and creates a large vortex that covers the first two ribs and reattaches with the wall after the third rib.

At low Reynolds number, the region of maximum Nusselt number is near the inlet and decreases towards the outlet for all ribs, except the rib of height $2.00 \mathrm{~mm}$, where the heat transfer near the centre of the heated wall is greatest, primarily owing to the separation created by the first rib, which results in two large vortices being formed before and after the second rib. For all roughened walls, the maximum heat transfer is downstream of the ribs and heat transfer decreases gradually towards the second rib, owing to the induced vortex downstream of the rib. Similar observations have been reported for flows in a heated duct with a roughened wall [34]. This indicates that the vortex size increases with rib height. Increasing the Reynolds number to 20000 results in a heat transfer reduction for all cases, the maximum reduction being for the rib of height $2.00 \mathrm{~mm}$, likely owing to the main flow being shifted away from the heated wall, as shown in Figure 8. At Reynolds numbers higher than 50000, the ribs have minimal effect on the heat transfer.
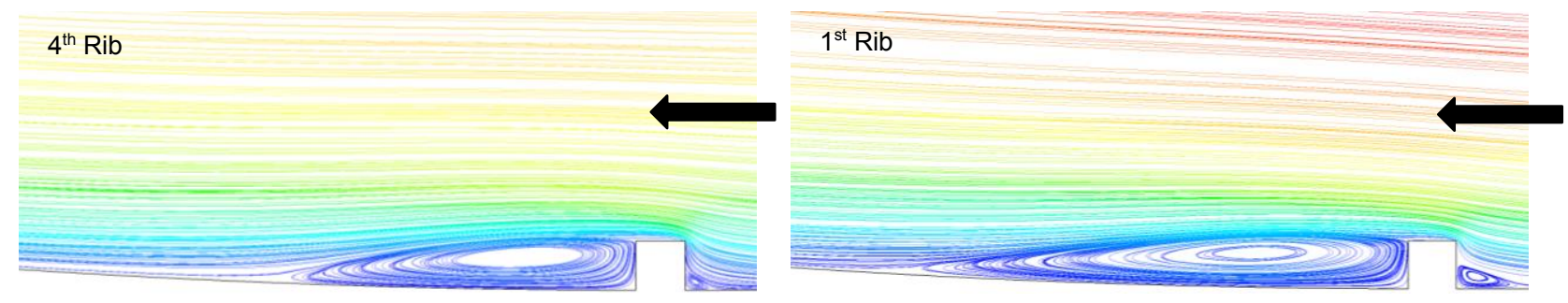

Figure 12 Streamline for rib height $0.25 \mathrm{~mm}$ near the first rib and the fourth rib.

The recirculation generated by the separation and reattachment of the flow by the rib is shown in Figure 12. The recirculation length downstream of the first rib is 10 times the height of the rib, while the recirculation length for the last rib is seven times the rib height. Furthermore, the turbulence intensity generated by the first rib is greater than the fourth rib, owing to the flow momentum and first encounter with the turbulator. Therefore, the peak Nusselt number downstream of the first rib is higher than that of the fourth rib (Figure 12).

\subsection{Entropy generation in swirl flow with roughened wall}

The entropy generation in the proposed model is divided into two parts: fluid entropy 


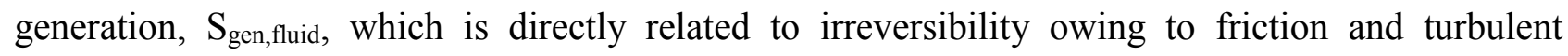

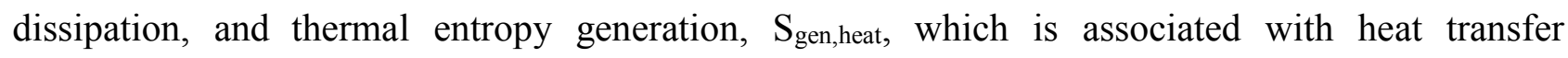
irreversibility. Figure 133 represents the thermal, fluid and the total entropy generation for the smooth vortex chamber at Reynolds number ranging from 10000 to 150000 . The result shows that, at low Reynolds numbers ranging from 10000 to 50000, the $S_{\text {gen,heat }}$ is higher than the $S_{\text {gen,fluid, while at }}$ Reynolds numbers higher than 80000, the $S_{\text {gen,fluid }}$ is larger than $S_{\text {gen,heat. This is ascribed to the high }}$ turbulence near the inlet where the inlet flow interacts with the swirl flow inside the chamber. The results show that at low Reynolds numbers the turbulence due to the interaction is minimal. The increase in $S_{\text {gen,heat }}$ with Reynolds number is similar to that observed with the Nusselt number shown in Figure 10 (b).

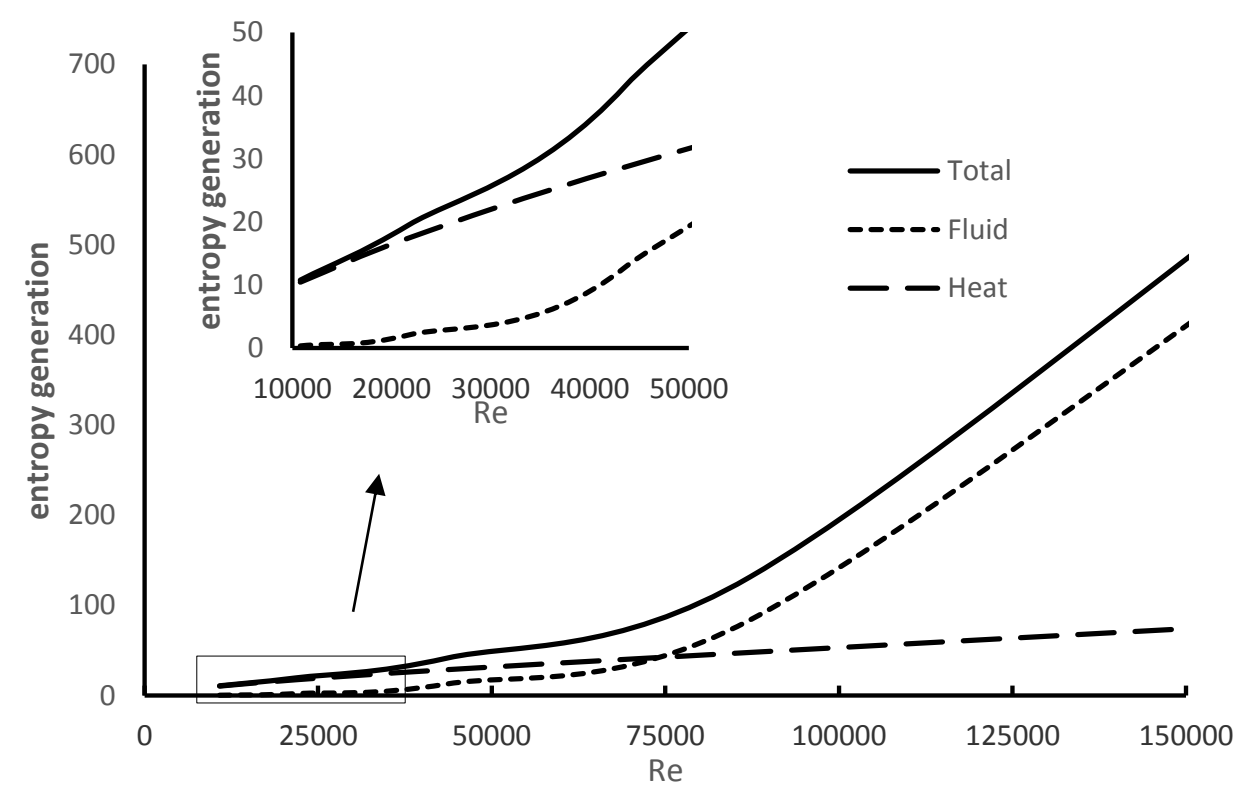

Figure 13 Total entropy generation, fluid entropy generation and thermal entropy generation for smooth-walled vortex chamber for $10000<R e<150000$.

The effect of rib height on entropy generation is shown in Figure 14; note that this should be compared to the panel inside Figure 12. At Reynolds number 10000, rib heights $0.50 \mathrm{~mm}$ and 1.00 mm generate maximum $S_{\text {gen,heat, while }} h_{\text {rib }}=2.00 \mathrm{~mm}$ shows minimal $S_{\text {gen, heat }}$. Additionally, the $S_{\text {gen,fluid }}$ increases gradually with increasing rib height owing to the turbulence generated from the rib, but remains small with respect to $S_{\text {gen,heat }}$ As the Reynolds number increases, the $S_{\text {gen,fluid }}$ increases significantly, particularly for $\mathrm{h}_{\mathrm{rib}}=0.25 \mathrm{~mm}$ and $0.50 \mathrm{~mm}$, owing to the turbulence generated from the ribs and the inlet mixing, as shown in Figure 144 (b) and (c).

However, at Reynolds number 40000 , it may be seen that $S_{\text {gen, the fluid has increased }}$

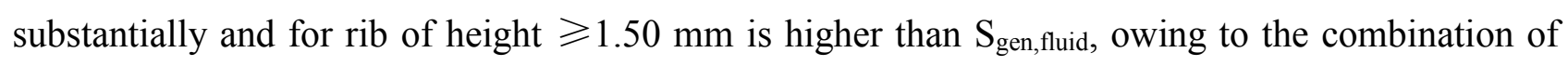


friction and inlet mixing, as shown in Figure 14 (d). This is caused by the high amount of turbulence generated from ribs, which continue along the chamber. For the maximum Reynolds number of 80000 we see that $S_{\text {gen,fluid }}$ is substantially larger than $S_{\text {gen,heat }}$ for all rib heights, and increases with increase in rib height.

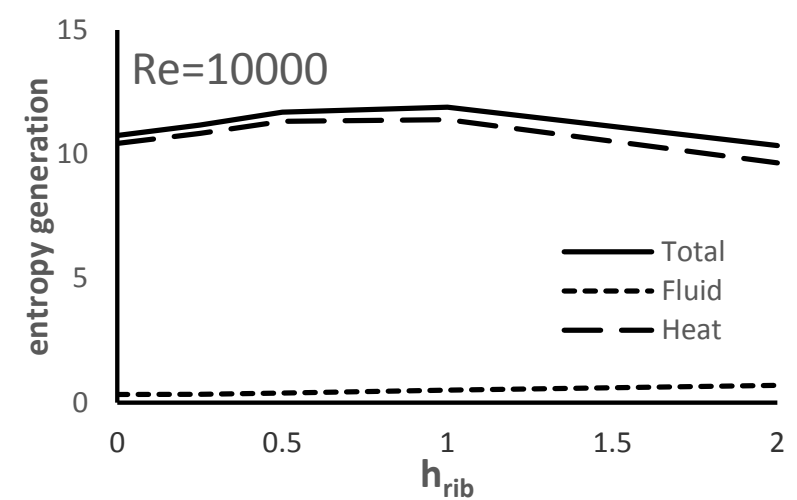

(a)

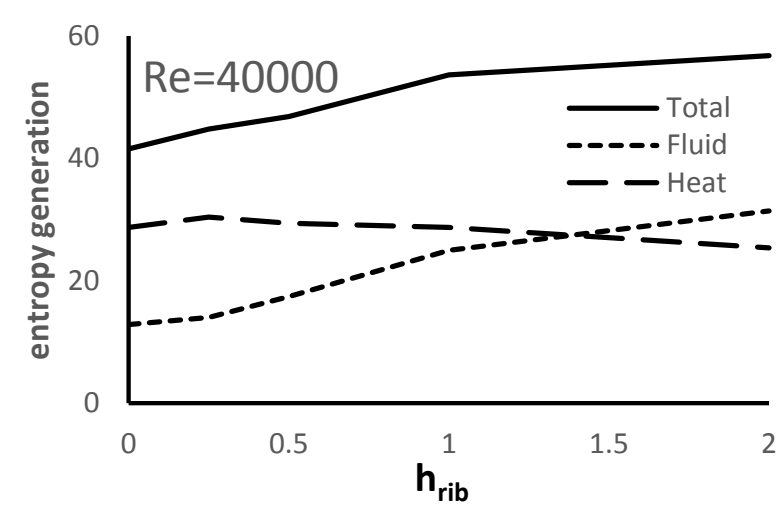

(c)

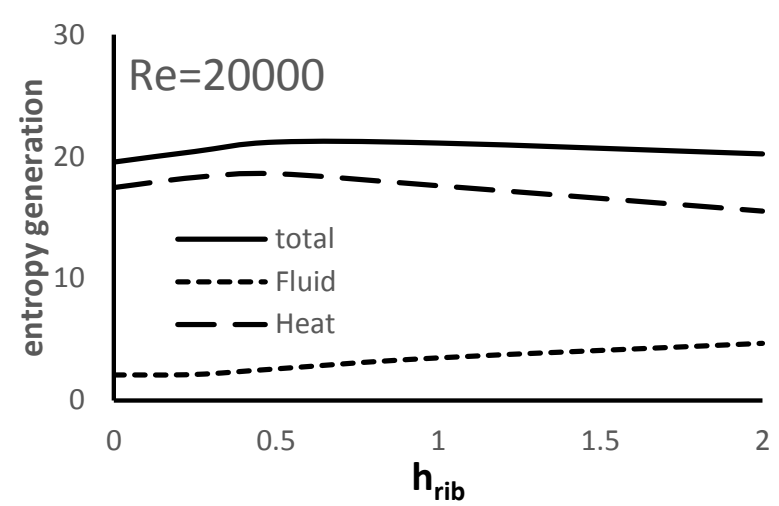

(b)

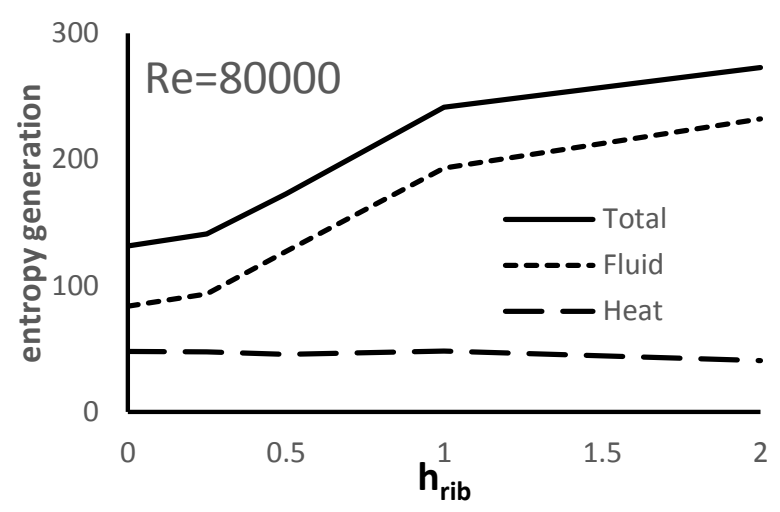

(d)

Figure 14 Total entropy generation, fluid entropy generation and thermal entropy generation for vortex chamber with rib roughened walls for $10000<R e<80000$. 


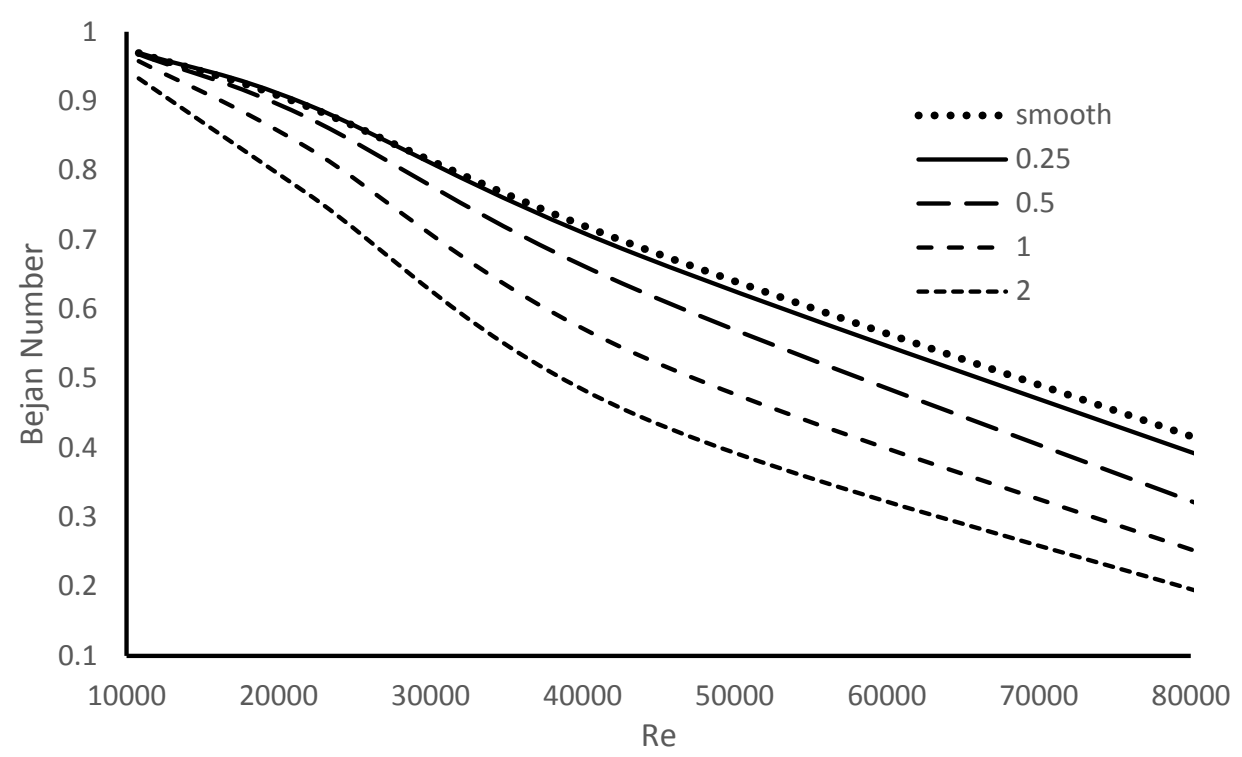

Figure 15 Bejan number for smooth and rib roughened walls, $10000<\operatorname{Re}<80000$.

The Bejan number is the ratio between entropy generation due to heat transfer over the total entropy generation. Figure 155 shows the relation between Bejan number and the Reynolds number for the vortex chamber with and without ribs. The Bejan number decreases as the Re number increases for all cases. Also, the Bejan number decreases as the rib height increases. The results show that, at higher Reynolds numbers, there is higher rib friction, giving lower convective heat transfer. This results in increasing the total entropy generation from friction and decreasing the entropy generation owing to convective heat transfer.

\section{Conclusion}

In this study, the effect on fluid flow characteristics of roughening the internal surface of a vortex chamber was investigated. Four square cross-section ribs of heights $0.25,0.50,1.00$ and 2.00 mm were used, with a range of Reynolds number from 10000 to 100000.

1- Numerical simulations were compared with experimental results for flow and heat transfer in a smooth vortex chamber. The results show a good match of velocity profiles with both the inner wall and the heated wall, with small deviation at the flow interaction regions at inlet and outlet. The difference between experimental and simulated values for the overall average Nusselt number was only $7.3 \%$.

2- The study indicates that the flow inside the vortex chamber is steady for a smooth wall and rib heights smaller than $0.25 \mathrm{~mm}$, but as either the rib height or the Reynolds number increases the flow become quasi-steady. When the rib height reaches $2.00 \mathrm{~mm}$, the flow is totally unsteady. 
3- Swirl cooling achieves a better thermal performance factor than jet impingement at both low and high Reynolds numbers, and at low Reynolds number produces a pressure loss that is significantly lower than for jet impingement.

4- The ribs affect the flow inside the chamber at Reynolds number less than 50000. When the rib height increases, the main flow velocity decreases at a point half way along the chamber. As the Reynolds number exceeds 50000, the ribs have minimal effect on the main flow. However, ribs with a height of $2.00 \mathrm{~mm}$ seriously disturb the flow inside the chamber, which results in a high-pressure drop.

5- The rib roughened wall produces superior thermal performance and heat transfer when the Reynolds number is less the 50000 for rib height of $0.25 \mathrm{~mm}$ compared to the smooth case. The maximum thermal performance takes place at Reynold number 10000 for rib height of $1.00 \mathrm{~mm}$ with a $17 \%$ increase. However, when the Reynolds number exceeds 50000, the ribs have a negative effect on the heat transfer compared to the smooth case

6- In a smooth chamber, the impact of heat transfer contributes significantly to the total entropy generation over the range tested of Reynolds numbers. In contrast, for the roughened wall when the Reynolds number exceeds 80000, the entropy generation due to a fluid is predominant, while the reverse occurs at low Reynolds numbers.

\section{Acknowledgments}

The authors acknowledge the valuable support and assistance provided by Public Authority for Applied Education and Training (PAAET), in state of Kuwait, through the financial support under project no. TS-17-11

\section{Nomenclature}

cp Pressure coefficient (-)

D Chamber diameter $(\mathrm{m})$

e $\quad \mathrm{h} /(\mathrm{H} / 2)$

$\mathrm{f} \quad$ Friction factor (-)

h Rib height (m)

$\mathrm{H} \quad$ Chamber inlet height $(\mathrm{m})$

I Enthalpy (J)

k Thermal conductivity $(\mathrm{W} / \mathrm{m} \mathrm{K})$

$\mathrm{p} \quad$ Pressure $(\mathrm{Pa})$

q Wall heat flux $\left(\mathrm{W} / \mathrm{m}^{2}\right)$

Re Reynolds number $4 \dot{m} / D \mu$ (-)

St Stanton number $N u / \operatorname{Re} P r(-)$

$\mathrm{S}_{\mathrm{E}} \quad$ Heat source $\left(\mathrm{J} / \mathrm{m}^{3} \mathrm{~s}\right)$

$\mathrm{S}_{\mathrm{M}} \quad$ External body force $\left(\mathrm{kg} / \mathrm{m}^{2} \mathrm{~s}^{2}\right)$

$\mathrm{S}_{\mathrm{r}} \quad$ Radiation intensity source term $\left(\mathrm{W} / \mathrm{m}^{2}\right)$

$\mathrm{T} \quad$ Temperature (K)

$\mathrm{t} \quad$ Time (s)

$\vec{\tau} \quad$ Viscous shear stress tensor $(\mathrm{Pa})$ 


$$
\begin{array}{ll}
\mathrm{u} & \text { Average velocity }(\mathrm{m} / \mathrm{s}) \\
\vec{u} & \text { Overall velocity vector }(\mathrm{m} / \mathrm{s})
\end{array}
$$

\section{Greek symbols}

$\xi \quad$ Total pressure loss coefficient (-)

$\Delta \quad$ Differential

$\mu \quad$ dynamic viscosity $\left(\mathrm{m}^{2} / \mathrm{s}\right)$

$\rho \quad$ Density $\left(\mathrm{kg} / \mathrm{m}^{3}\right)$

\section{Subscripts}

$\begin{array}{ll}\text { in } & \text { Inlet } \\ \text { b } & \text { Bulk } \\ \text { w } & \text { Wall } \\ \text { o } & \text { Baseline state }\end{array}$

\section{References}

[1] Z. Liu, J. Li, Z. Feng, T. Simon, Numerical study on the effect of jet nozzle aspect ratio and jet angle on swirl cooling in a model of a turbine blade leading edge cooling passage, International Journal of Heat and Mass Transfer. 90 (2015) 986-1000.

[2] B. Zhang, X. Guo, Z. Yang, Analysis on the fluid flow in vortex tube with vortex periodical oscillation characteristics, International Journal of Heat and Mass Transfer. 103 (2016) 11661175 .

[3] B. Kobiela, B.A. Younis, B. Weigand, O. Neumann, A computational and experimental study of thermal energy separation by swirl, International Journal of Heat and Mass Transfer. 124 (2018) 11-19.

[4] F. Wassermann, S. Grundmann, M. Kloss, H.-P. Schiffer, Swirl flow investigations on the enhancement of heat transfer processes in cyclone cooling ducts, in: ASME Turbo Expo, 2012: pp. 527-542.

[5] X. Fan, L. Li, J. Zou, J. Wang, F. Wu, Local heat transfer of vortex cooling with multiple tangential nozzles in a gas turbine blade leading edge cooling passage, International Journal of Heat and Mass Transfer. 126 (2018) 377-389.

[6] Y. Luan, C. Du, X. Fan, J. Wang, L. Li, Investigations of flow structures and heat transfer in a swirl chamber with different inlet chambers and various aerodynamic parameters, International Journal of Heat and Mass Transfer. 118 (2018) 551-561.

[7] H. Kaya, F. Günver, V. Kirmaci, Experimental investigation of thermal performance of parallel connected vortex tubes with various nozzle materials, Applied Thermal Engineering. 136 (2018) 287-292.

[8] M. Darvish Damavandi, S.M. Mousavi, H. Safikhani, Pareto optimal design of swirl cooling chambers with tangential injection using CFD, GMDH-type of ANN and NSGA-II algorithm, International Journal of Thermal Sciences. 122 (2017) 102-114.

[9] J.P.C.W. Ling, P.T. Ireland, N.W. Harvey, Measurement of heat transfer coefficient distributions and flow field in a model of a turbine blade cooling passage with tangential injection, ASME Conference Proceedings. 2006 (2006) 325-340.

[10] N. Wang, A.F. Chen, M. Zhang, J.-C. Han, Turbine blade leading edge cooling with one row of normal or tangential impinging jets, Journal of Heat Transfer. 140 (2018) 62201-62210.

[11] Y. Matsuno, Y. Fukushima, S. Matsuo, T. Hashimoto, T. Setoguchi, H.D. Kim, Investigation on temperature separation and flow behaviour in vortex chamber, Journal of Thermal Science. 24 (2015) 149-154.

[12] M. Bruschewski, C. Scherhag, H.-P. Schiffer, S. Grundmann, Influence of channel geometry 
and flow variables on cyclone cooling of turbine blades, Journal of Turbomachinery. 138 (2016) 061005.

[13] C. Du, L. Li, X. Wu, Z. Feng, Effect of jet nozzle geometry on flow and heat transfer performance of vortex cooling for gas turbine blade leading edge, Applied Thermal Engineering. 93 (2016) 1020-1032.

[14] C. Du, L. Li, X. Fan, Z. Feng, Rotational influences on aerodynamic and heat transfer behavior of gas turbine blade vortex cooling with bleed holes, Applied Thermal Engineering. 121 (2017) 302-313.

[15] X. Fan, C. Du, L. Li, S. Li, Numerical simulation on effects of film hole geometry and mass flow on vortex cooling behavior for gas turbine blade leading edge, Applied Thermal Engineering. 112 (2017) 472-483.

[16] S.E. Rafiee, M.M.M. Sadeghiazad, Efficiency evaluation of vortex tube cyclone separator, Applied Thermal Engineering. 114 (2017) 300-327.

[17] S.M. Mousavi, B. Ghadimi, F. Kowsary, Numerical study on the effects of multiple inlet slot configurations on swirl cooling of a gas turbine blade leading edge, International Communications in Heat and Mass Transfer. 90 (2018) 34-43.

[18] C. Biegger, B. Weigand, Flow and heat transfer measurements in a swirl chamber with different outlet geometries, Experiments in Fluids. 56 (2015) 78.

[19] G. Lin, K. Kusterer, D. Bohn, T. Sugimoto, R. Tanaka, M. Kazari, Investigation on heat transfer enhancement and pressure loss of double swirl chambers cooling, Propulsion and Power Research. 2 (2013) 177-187.

[20] C.Y. Chang, S. Jakirlić, K. Dietrich, B. Basara, C. Tropea, Swirling flow in a tube with variably-shaped outlet orifices: An LES and VLES study, International Journal of Heat and Fluid Flow. 49 (2014) 28-42.

[21] C. Biegger, C. Sotgiu, B. Weigand, Numerical investigation of flow and heat transfer in a swirl tube, International Journal of Thermal Sciences. 96 (2015) 319-330.

[22] Y. Liu, Y. Rao, B. Weigand, Heat transfer and pressure loss characteristics in a swirl cooling tube with dimples on the tube inner surface, International Journal of Heat and Mass Transfer. 128 (2019) 54-65.

[23] M. Al-Ajmi, N. Syred, P. Bowen, A. Khalatov, M.A. Al-Shaghdari, R. M. Al-Ajmi, Nick Syred, Phil J. Bowen, A. Khalatov, M.A. Al-Shaghdari, A comparison of cfd and lda studies of internal vortex cooling systems for turbine blades, Journal of Flow Visualization and Image Processing. 5 (1998) 197-210.

[24] A. Khalatov, N. Syred, P.J. Bowen, I.R. Al-Ajm, Enhanced cyclone cooling technique for high performance gas turbine blades, in: 12th International Heat Transfer Conference, Grenoble, France, 2002: pp. 1-6.

[25] A. Gupta, R. Kumar, Three-dimensional turbulent swirling flow in a cylinder: Experiments and computations, International Journal of Heat and Fluid Flow. 28 (2007) 249-261.

[26] M.L. Shur, P.R. Spalart, M.K. Strelets, A.K. Travin, A hybrid RANS-LES approach with delayed-DES and wall-modelled LES capabilities, International Journal of Heat and Fluid Flow. 29 (2008) 1638-1649.

[27] M.S. Gritskevich, A. V Garbaruk, J. Schütze, F.R. Menter, Development of DDES and IDDES Formulations for the k- $\omega$ Shear Stress Transport Model, Flow, Turbulence and Combustion. 88 (2012) 431-449.

[28] C.M. Rhie, W.L. Chow, Numerical study of the turbulent flow past an airfoil with trailing edge separation, AIAA Journal. 21 (1983) 1525-1532.

[29] S. Armfield, R. Street, The fractional-step method for the navier-stokes equations on staggered grids: the accuracy of three variations, Journal of Computational Physics. 153 (1999) 660-665.

[30] A.H. Alenezi, A. Almutairi, H.M. Alhajeri, A. Addali, A.A.A. Gamil, Flow structure and heat transfer of jet impingement on a rib-roughened flat plate, Energies. 11 (2018).

[31] A. Almutairi, Computation of Conjugate Heat Transfer in Impinging Flows, 2010. 
[32] S. Xie, Z. Liang, L. Zhang, Y. Wang, A numerical study on heat transfer enhancement and flow structure in enhanced tube with cross ellipsoidal dimples, International Journal of Heat and Mass Transfer. 125 (2018) 434-444.

[33] A. Bejan, A Study of entropy generation in fundamental convective heat transfer, Journal of Heat Transfer. 101 (1979) 718-725.

[34] F. Kock, H. Herwig, Local entropy production in turbulent shear flows: a high-Reynolds number model with wall functions, International Journal of Heat and Mass Transfer. 47 (2004) 2205-2215.

[35] Y. Rao, C. Biegger, B. Weigand, Heat transfer and pressure loss in swirl tubes with one and multiple tangential jets pertinent to gas turbine internal cooling, International Journal of Heat and Mass Transfer. 106 (2017) 1356-1367. 
Numerical investigation on heat transfer performance and flow characteristics in a roughened vortex chamber

\author{
Alhajeri, Hamad M.
}

Elsevier

Alhajeri HM, Almutairi A, Alenezi AH, Gamil AA. (2019) Numerical investigation on heat transfer performance and flow characteristics in a roughened vortex chamber. Applied Thermal

Engineering, Volume 153, May 2019, pp. 58-68

https://doi.org/10.1016/j.applthermaleng.2019.02.071

Downloaded from Cranfield Library Services E-Repository 